\title{
Criptógamos do Parque Estadual das Fontes do Ipiranga, São Paulo, SP. Algas, 29: Euglenophyceae (família Peranemaceae)
}

\author{
Carlos Eduardo de Mattos Bicudo ${ }^{1}$
}

Recebido: 16.10.2009; aceito: 17.06.2010

\begin{abstract}
Cryptogams of the "Parque Estadual das Fontes do Ipiranga", São Paulo, SP. Algae, 29: Euglenophyceae (family Peranemaceae)). Taxonomic survey of representatives of family Peranemaceae (Euglenophyceae) in the Parque Estadual das Fontes do Ipiranga, São Paulo, Brazil. Six genera (Dinematomonas, Entosiphon, Heteronema, Parmidium, Peranema and Urceolus) and 36 species, but no varieties and taxonomic formae that are not the typical of their respective species and variety were identified. One species, Entosiphon skvortzovii C. Bicudo, is described as new to Science. Genus presenting the greatest number of infrageneric taxa was Entosiphon, with 22. Follow Parmidium with 9, Heteronema with 2 and Dinematomonas, Peranema and Urceolus with a single species each. All species were collected from a single locality each.
\end{abstract}

Key words: Brazil, Dinematomonas, Entosiphon, Heteronema, Parmidium, Peranema, Urceolus

RESUMO - (Criptógamos do Parque Estadual das Fontes do Ipiranga, São Paulo, SP. Algas. 29: Euglenophyceae (família Peranemaceae)). Levantamento florístico dos representantes da família Peranemaceae (Euglenophyceae) do Parque Estadual das Fontes do Ipiranga, São Paulo, Brasil. Seis gêneros (Dinematomonas, Entosiphon, Heteronema, Parmidium, Peranema e Urceolus) e 36 espécies, mas nenhuma variedade ou forma taxonômica que não sejam as típicas de suas respectivas espécies e variedades foram identificadas. Uma espécie, Entosiphon skvortzovii C. Bicudo, foi descrita como nova para a Ciência. O gênero representado pelo maior número de espécies foi Entosiphon, com 22. Seguem-no Parmidium com nove, Heteronema com duas e Dinematomonas, Peranema e Urceolus, cada um com uma espécie apenas. Todas as espécies foram coletadas, cada uma, em uma única localidade.

Palavras-chave: Brasil, Dinematomonas, Entosiphon, Heteronema, Parmidium, Peranema, Urceolus

\section{Introdução}

A literatura referente às Peranemaceae do PEFI, Parque Estadual das Fontes do Ipiranga, consta apenas de seis trabalhos, todos realizados pelo Prof. Dr. Boris Vassilievich Skvortzov quando de sua permanência no Instituto de Botânica, em São Paulo.

Skvortzov (1966) foi o primeiro trabalho e nele propôs uma emenda à descrição original do gênero Heteronema e descreveu duas espécies novas do mesmo gênero a partir de material do PEFI. Além destas duas, relacionou 11 outras espécies já descritas em Huber-Pestalozzi (1955), três que já haviam sido coletadas por ele mesmo em Harbin. Além disso, descreveu pioneiramente sete outras de materiais de Harbin, nordeste da China, e da cidade de São Paulo, Brasil.

O trabalho seguinte é a proposição do gênero Huber-Pestalozziamonas simultaneamente à descrição de 12 espécies, 10 das quais são novas para a Ciência, sendo três (H. acquae-purae, H. obliqua e H. simplicia) para a área do PEFI. O material examinado constou de três amostras, duas delas coletadas em 1963 e uma terceira em 1965, todas pelo próprio B.V. Skvortzov, de ambientes não precisamente identificados no Parque (Skvortzov 1967).

Dois anos mais tarde, Skvortzov (1969) descreveu 28 gêneros de representantes de Euglenophyceae despigmentadas que classificou na família Astasiaceae, sete dos quais (Acusmonas, Bicudomonas, Calawaymonas, Eneidamonas, Hoehnemonas, Liangiana, Mariniamonas e Nilzamonas) foram propostos a partir de material de diferentes localidades no PEFI. Todas essas localidades não foram, contudo, identificadas de maneira precisa, constando de todas apenas informação vaga como, por exemplo, cavidade com água pluvial temporária, água impura, água de fonte, entre folhas de gramíneas e água estagnada

1. Instituto de Botânica, Caixa Postal 3005, 01061-970 São Paulo, SP, Brasil. cbicudo@terra.com.br 
temporária. Nilzamonas (N. saprophyticum) foi descrita de material em cultivo temporário feito a partir de esterco eqüino.

O gênero Entosiphon foi estudado em três oportunidades. Na primeira delas, Skvortzov \& Noda (1968) identificaram e propuseram, como novas para a Ciência, nove espécies coletadas na cidade de São Paulo e arredores, três das quais provieram de ambientes situados no PEFI (E. ellipticum Skvortzov \& Noda, E. longistriatum Skvortzov \& Noda e E. utriculariae Skvortzov \& Noda). Na segunda, Skvortzov \& Noda (1969) identificaram e propuseram como novas 18 espécies do referido gênero também para a cidade de São Paulo e arredores, sendo que oito delas (E. aerophyllum Skvortzov \& Noda, E. brevisiphon Skvortzov \& Noda, E. cymbellae Skvortzov \& Noda, E. dentatum Skvortzov \& Noda, E. eichhorniae Skvortzov \& Noda, E. fontinalis Skvortzov \& Noda, E. spiralis Skvortzov \& Noda e E. utriculariae Skvortzov \& Noda) foram baseadas em material proveniente do PEFI. E na terceira, 10 espécies (E. anaerobicum Skvortzov \& Noda, E. brevilanceolatum Skvortzov \& Noda, E. caudatum Skvortzov \& Noda, E. longiusculum Skvortzov \& Noda, E. merdae Skvortzov \& Noda, E. nasutum Skvortzov \& Noda, E. pluvialis Skvortzov \& Noda, E. pulchrum Skvortzov \& Noda, E. stagnalis Skvortzov \& Noda e E. triquetrum Skvortzov \& Noda) foram propostas por Skvortzov \& Noda (1970) a partir de material exclusivamente do PEFI.

Embora haja menção em certos trabalhos como, por exemplo, em Skvortzov \& Noda $(1969,1970)$, de que o material estudado foi depositado no Herbário Científico do Estado "Maria Eneyda P. Kauffmann Fidalgo" (SP), tal fato jamais aconteceu. Conclusão, as descrições e ilustrações constituem toda a documentação original de cada espécie referida nos diversos trabalhos.

\section{Material e métodos}

O presente trabalho foi baseado quase que exclusivamente em material da literatura. As amostras coletadas não contiveram material de Peranemaceae e, portanto, não houve material depositado no Herbário Científico do Estado "Maria Eneyda P. Kauffmann Fidalgo" (SP) do Instituto de Botânica da Secretaria do Meio Ambiente do Estado de São Paulo.

Visando a mais pronta localização, gêneros e espécies foram atualmente apresentados em ordem alfabética crescente, estas últimas dentro dos gêneros competentes. Espécies que constam unicamente da literatura, isto é, que não foram reencontradas durante o presente levantamento tiveram seus nomes citados nas chaves de identificação e no texto precedidos por um asterisco.

A despeito da coleta intensa durante quase 40 anos no PEFI, nenhum material de Peranemaceae, exceto de Peranema, foi atualmente reencontrado. Assim, todo o conhecimento sobre os materiais tratados neste trabalho foi extraído da literatura. Pior, das descrições originais de cada espécie, que constituem os únicos documentos sobre cada uma. Nestas condições, os nomes na literatura devem prevalecer até que material de cada uma seja reencontrado e estudos mais aprofundados permitam o melhor conhecimento de cada espécie.

\section{Resultados e Discussão}

O sistema de classificação adotado foi o de Bourrelly (1970), por ser o único que inclui praticamente todos os gêneros até então conhecidos, classificados segundo critérios uniformemente aplicados a todo o universo dos gêneros nele contidos. Os sete gêneros presentemente identificados para o PEFI têm a seguinte situação sistemática:

Divisão Euglenophyta

Classe Euglenophyceae

Ordem Euglenales

Família Peranemaceae

Dinematomonas

Entosiphon

Heteronema

Parmidium (inclui

Bicudomonas, Hoehnemonas, Huberpestalozziamonas, Liangiana, Mariniamonas, Menoidiomonas e Nilzamonas)

Peranema

Urceolus

\section{PERANEMACEAE}

Indivíduos unicelulares, isolados, incolores, de vida livre, ativamente móveis na fase vegetativa com um ou dois flagelos. No último caso, o flagelo anterior é mais espesso e vai sempre dirigido para frente enquanto o indivíduo se desloca; e o flagelo posterior é relativamente mais delicado (menos espesso) e dirigido para trás, comumente colado ao corpo de célula enquanto ela se desloca. Este flagelo 
pode ser reduzido e até mesmo inexistir, o indivíduo apresentando-se uniflagelado. A película é, em geral, extremamente delicada, de modo a garantir a metabolia na maioria das espécies desta família. A nutrição é fagotrófica ou, mais raramente, por osmotrofismo.

A literatura classifica nesta família os gêneros cujas organelas para ingestão (antes denominadas aparelho paravestibular em seu conjunto) são bem visíveis ao microscópio óptico. Constituem as organelas para ingestão o citóstoma, a citofaringe ou goela e os vacúolos digestivos. Em alguns casos, um ou dois bastonetes faringeanos podem existir paralelos à citofaringe. A bem da verdade, essa facilidade de visualização das organelas para ingestão nem sempre existe e há casos onde nada se vê, justificando plenamente a afirmação em Bourrelly (1970) de que é difícil definir a família Peranemaceae.

\section{Dinematomonas Silva}

Indivíduos unicelulares não-metabólicos, de vida livre e hábito isolado. A forma da célula é elipsoidal, com a seção transversal levemente comprimida dorsiventralmente. A película é helicoidalmente estriada. Os dois flagelos inseremse anterior e subapicalmente na célula, no fundo de um reservatório. Esses flagelos possuem tamanhos nitidamente distintos entre si, sendo que o menor e também o mais delicado dos dois vibra intensamente e vai sempre estirado para frente provocando o deslocamento da célula; e o maior e mais grosseiro vai voltado para trás, colado ao corpo da célula, podendo formar um gancho assim que emerge do reservatório e é o responsável pela orientação do deslocamento da célula. Ocorre um bastonete faringeano nos representantes deste gênero, isto é, um tipo de tubo longo e mais ou menos cônico que faz parte do sistema paravestibular. A função deste tubo permanece ainda desconhecida.

O nome Dinematomonas Silva 1960 substituiu Dinema Perty 1851, por este ser um homônimo posterior de Dinema Lindley 1826, uma orquídea (Silva 1960).

Apenas uma espécie foi identificada.

* D. griseola (Perty) Silva, Taxon 9: 20. $1960 \equiv$ Dinema griseolum Perty, Zur Kenntnis kleinster Lebensformen nach Bau, Funktionen, Systematik, mit Specialverzeichniss der in Schweiz beobachtetenen. 169. 1852.

Figura 1
Indivíduo unicelular, solitário, livre-natante, não-metabólico; célula elipsoidal, pólo anterior levemente chanfrado em bisel, pólo posterior amplamente arredondado, 67-75 $\mu \mathrm{m}$ compr., 27-37,5 $\mu \mathrm{m}$ larg.; seção transversal dorsiventralmente pouco comprimida, margem lisa; película extremamente delgada, estriada, estrias torcidas para a esquerda (levógiras), 14-16 ao longo da célula; flagelos 2, de tamanhos notadamente desiguais, o menor e mais delicado tão longo quanto a célula, estirado frontalmente, o maior e mais grosseiro ca. 1,5 vez o comprimento da célula, voltado para trás, colado ao corpo da célula, podendo formar um gancho assim que emerge do reservatório; bastonete faringeano ca. $1 / 5$ do corpo celular.

Hábitat: planctônico.

A única referência à ocorrência de Dinematomonas griseola (Perty) Silva no Brasil está em Bicudo \& Bicudo (1970), que a identificaram ainda sob seu basiônimo, Dinema griseolum Perty, a partir de material coletado no hidrofitotério do Jardim Botânico de São Paulo, logo acima da camada de sedimentos. Tais sedimentos são extremamente ricos em matéria orgânica resultante da decomposição das plantas aquáticas do próprio local.

\section{Entosiphon Stein}

Indivíduos unicelulares livre-natantes, nãometabólicos e de hábito isolado. A forma da célula varia entre obovóide, elipsóide ou oblonga, porém, com a seção transversal sempre levemente comprimida dorsiventralmente. A película pode ser estriada ou costelada e ocorrem entre seis e 12 estrias ou costelas longitudinais separadas umas das outras por depressões mais ou menos rasas. Tanto as estrias quanto as costelas são melhor visíveis próximo ao pólo anterior da célula. Os dois flagelos inserem-se anterior e apicalmente na célula, possuem tamanhos distintos entre si e o menor vibra intensamente e vai sempre estirado frontalmente enquanto a célula se desloca e o maior vibra pouco e vai voltado para trás, colado ao corpo da célula. Enquanto o primeiro faz a célula se mover, o segundo orienta seu deslocamento. A característica diagnóstica dos representantes deste gênero é o sifão ou bastonete faringeano, isto é, um tipo de tubo longo e mais ou menos cônico que faz parte do chamado sistema paravestibular. A função deste tubo constituído por três camadas de fibrilas e um septo transversal anterior também fibroso ainda permanece desconhecida. 


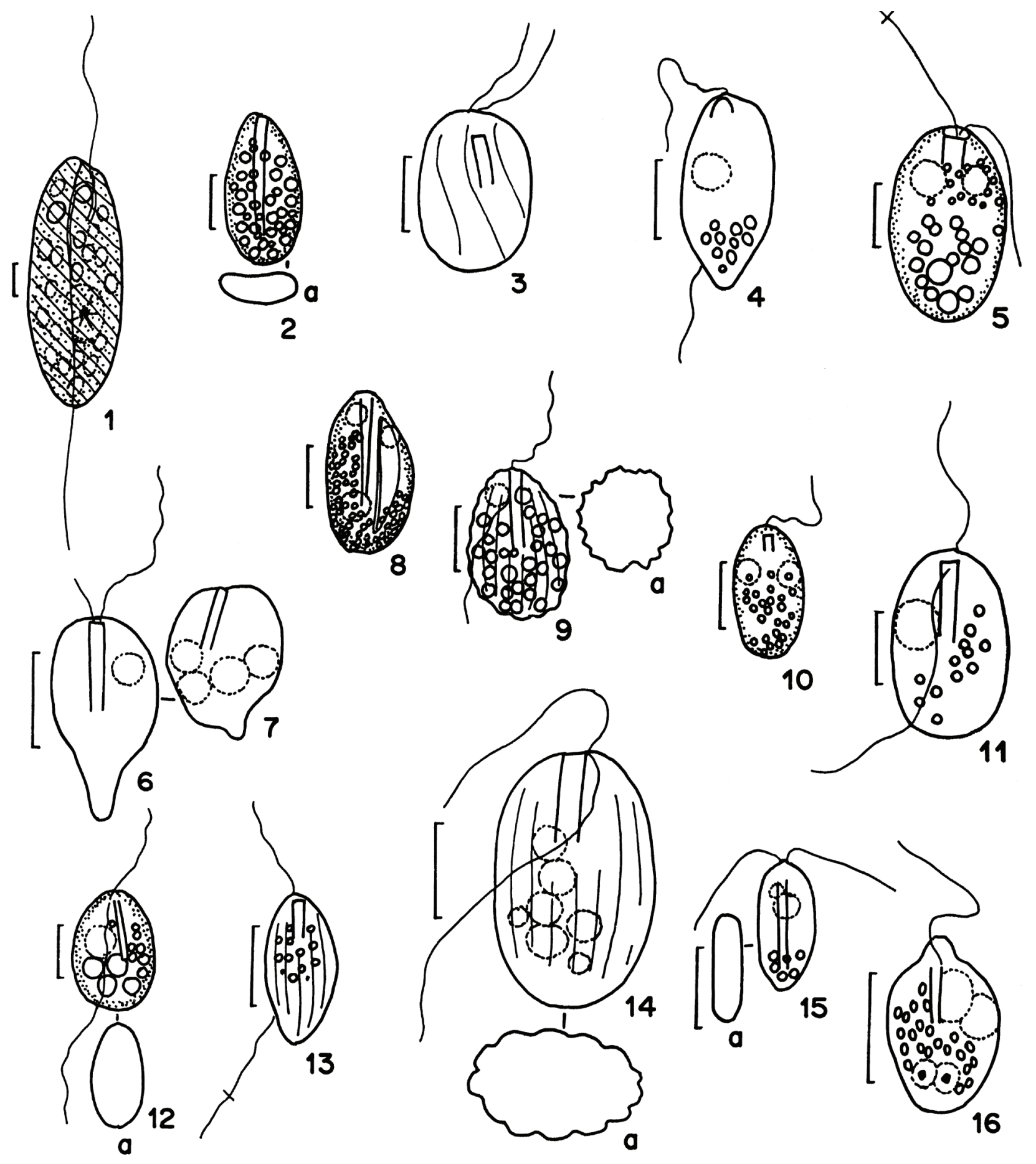

Figuras 1-16. Espécies de Paranemaceae do Parque Estadual das Fontes do Ipiranga. 1. Dinematomonas griseola (Bicudo \& Bicudo 1970). 2. Entosiphon aerophyllum (Skvortzov \& Noda 1969). 3. E. anaerobicum (Skvortzov \& Noda 1970). 4. E. brevilanceolatum (Skvortzov \& Noda 1970). 5. E. brevisiphon (Skvortzov \& Noda 1969). 6-7. E. caudatum (Skvortzov \& Noda 1970). 8. E. cymbellae (Skvortzov \& Noda 1969). 9. E. dentatum (Skvortzov \& Noda 1969). 10. E. eichhorniae (Skvortzov \& Noda 1969). 11. E. ellipticum (Skvortzov \& Noda 1968). 12. E. fontinalis (Skvortzov \& Noda 1969). 13. E. longiusculum (Skvortzov \& Noda 1970). 14. E. longistriatum (Skvortzov \& Noda 1968). 15. E. merdae (Skvortzov \& Noda 1970). 16. E. nasutum var. nasutum (Skvortzov \& Noda 1970). Barras das escalas $=$ $10 \mu \mathrm{m}$.

Figures 1-16. Species of Paranemaceae from the "Parque Estadual das Fontes do Ipiranga". 1. Dinematomonas griseola (Bicudo \& Bicudo 1970). 2. Entosiphon aerophyllum (Skvortzov \& Noda 1969). 3. E. anaerobicum (Skvortzov \& Noda 1970). 4. E. brevilanceolatum (Skvortzov \& Noda 1970). 5. E. brevisiphon (Skvortzov \& Noda 1969). 6-7. E. caudatum (Skvortzov \& Noda 1970). 8. E. cymbellae (Skvortzov \& Noda 1969). 9. E. dentatum (Skvortzov \& Noda 1969). 10. E. eichhorniae (Skvortzov \& Noda 1969). 11. E. ellipticum (Skvortzov \& Noda 1968). 12. E. fontinalis (Skvortzov \& Noda 1969). 13. E. longiusculum (Skvortzov \& Noda 1970). 14. E. longistriatum (Skvortzov \& Noda 1968). 15. E. merdae (Skvortzov \& Noda 1970). 16. E. nasutum var. nasutum (Skvortzov \& Noda 1970). Scale bars $=10 \mu \mathrm{m}$. 
Chave para as espécies e variedade de Entosiphon

1. Película estriada

2. Seção transversal da célula triangular * E. triquetrum

2. Seção transversal da célula elíptica alongada

3. Margem da célula em seção transversal denteada ou crenulada

4. Margem da célula em seção transversal denteada

* E. dentatum

4. Margem da célula em seção transversal crenulada

5. Margem da célula em seção transversal crenulada apenas de um lado

* E. spiralis

5. Margem da célula em seção transversal crenulada em toda periferia

6. Célula subcircular * E. utriculariae

6. Célula elíptica ou oblonga

7. Célula elíptica

*. longiusculum

7. Célula oblonga

* E. longistriatum

3. Margem da célula em seção transversal lisa

8. Célula amplamente elipsóide a quase esférica

* E. sampaulense

8. Célula subfusiforme ou oblonga

9. Célula subfusiforme *E.pulchrum

9. Célula oblonga

10. Seção transversal da célula amplamente elíptica, estrias longitudinais, 6-8 visíveis ao longo da célula

* E. skvortzovii

10. Seção transversal da célula dorsiventralmente bastante comprimida, estrias levógiras, 3-4 visíveis ao longo da célula

*E. anaerobicum

1. Película lisa

11. Célula em forma de raquete

* E. caudatum

11. Célula elíptica, oblonga, regularmente ovóide, obovóide alongada ou curto-cilíndrica

12. Célula mais ou menos elíptica

13. Bastonete faringeano ca. $1 / 5$ do corpo celular

13. Bastonete faringeano ca. $1 / 10$ do corpo celular

* E. brevisiphon

* E. brevilanceolatum

12. Célula, oblonga, ovóide, regularmente obovóide, obovóide alongada ou curto-cilíndrica

14. Célula curto-cilíndrica

* E. stagnalis

14. Célula oblonga, ovóide, regularmente obovóide a obovóide alongada

15. Célula oblonga

* E. ellipticum

15. Célula regularmente ovóide, ovóide alongada, regularmente obovóide a obovóide alongada

16. Célula regularmente ovóide ou ovóide alongada

17. Bastonete faringeano curto $(\leq 1 / 2$ do comprimento celular $)$

18 . Bastonete faringeano $\leq 1 / 5$ do comprimento celular * E. eichhorniae

18 . Bastonete faringeano $\equiv 1 / 2$ do comprimento celular * E. fontinalis

17. Bastonete faringeano longo ( $\geq 2 / 3$ do comprimento celular)

19. Bastonete faringeano $\equiv 2 / 3$ do comprimento celular * E. cymbellae

19 . Bastonete faringeano $\geq 4 / 5$ do comprimento celular

* E. aerophyllum

16. Célula regularmente obovóide a obovóide alongada

20. Bastonete faringeano longo (ca. $4 / 5$ do comprimento celular)

* E. merdae

20 . Bastonete faringeano curto ( $\leq 1 / 2$ do comprimento celular)

21. Bastonete faringeano ca. $1 / 2$ do comprimento celular

21. Bastonete faringeano ca. $1 / 3$ do comprimento celular

* E. pluvialis

* E. nasutum var. nasutum

* E. aerophyllum Skvortzov \& Noda, Science Reports of Niigata University, sér. D, 6: 90, fig. 13. 1969.

Figura 2
Indivíduo unicelular, solitário, livre-natante, nãometabólico; célula ovóide alongada, pólo anterior acuminado truncado, pólo posterior amplamente arredondado, ca. 28,8 $\mu \mathrm{m}$ compr., ca. 13,8 $\mu \mathrm{m}$ larg.; 
seção transversal dorsiventralmente comprimida, oblonga alongada, encurvada, margem lisa; película extremamente delgada, lisa; flagelos 2, desiguais; bastonete faringeano ca. $4 / 5$ do corpo celular.

Hábitat: planctônico.

Entosiphon aerophyllum Skvortzov \& Noda lembra, até certo ponto, E. cymbellae Skvortzov $\&$ Noda, do qual difere, principalmente, pelo comprimento do bastonete farigeano, que no primeiro é pouco mais do que quatro quintos do comprimento celular e no segundo, menor do que dois terços.

Skvortzov \& Noda (1969) referem a existência de flagelos distintos entre si, mas não os ilustra nem identificam a dessemelhança entre eles, se de tipo ou tamanho.

* E. anaerobicum Skvortzov \& Noda, Science Reports of Niigata University, sér. D, 7: 59, fig. 9. 1970.

Figura 3

Indivíduo unicelular, solitário, livre-natante, nãometabólico; célula oblonga, pólos anterior e posterior amplamente arredondados, 22,7-23,6 $\mu$ m compr., ca. 15,4 $\mu \mathrm{m}$ larg.; seção transversal dorsiventralmente bastante comprimida, elíptica alongada, margem lisa; película extremamente delgada, estriada, estrias torcidas para a esquerda (levógiras), 3-4 ao longo da célula; flagelos 2, de tamanhos levemente desiguais; bastonete faringeano ca. 1/3 do corpo celular.

Hábitat: planctônico.

Skvortzov \& Noda (1970) referiram a forma da célula como em geral elíptica, raro obovada, porém, nenhum dos dois exemplares ilustrados mostra tais formas, mas oblonga, com as margens um pouco mais abauladas no exemplar figurado à direita e quase reta no da esquerda.

* E. brevilanceolatum Skvortzov \& Noda, Science Reports of Niigata University, sér. D, 7: 59, fig. 8. 1970.

Figura 4

Indivíduo unicelular, solitário, livrenatante, não-metabólico; célula subelíptica, pólo anterior amplamente arredondado, pólo posterior uniformemente afilado, quase mamilado, 11$15 \mu \mathrm{m}$ compr., 5,1-7 $\mu \mathrm{m}$ larg.; seção transversal dorsiventralmente bastante comprimida, elíptica alongada, margem lisa; película extremamente delgada, lisa; flagelos 2, anterior aproximadamente tão longo quanto o corpo da célula, posterior uma vez e meia mais longo que o corpo da célula; bastonete faringeano ca. 1/10 do corpo celular.

Hábitat: planctônico.

Entre as espécies coletadas no PEFI, esta é bastante característica pela forma subelíptica de sua célula, cujo pólo anterior é amplamente arredondado e o posterior uniformemente afilado, quase mamilado.

Skvortzov \& Noda (1970) identificaram a existência de seção celular transversal dorsiventralmente comprimida, elíptica, alongada, de margem lisa, porém, não a ilustraram.

* E. brevisiphon Skvortzov \& Noda, Science Reports of Niigata University, sér. D, 6: 98, fig. 2. 1969.

Figura 5

Indivíduo unicelular, solitário, livre-natante, não-metabólico; célula amplamente elíptica, pólos anterior e posterior iguais, acuminado-arredondados, ca. $37 \mu \mathrm{m}$ compr., ca. $18 \mu \mathrm{m}$ larg.; seção transversal ?, margem lisa; película extremamente delgada, lisa; flagelos 2, aproximadamente tão longos ou pouco mais curtos que o corpo da célula; bastonete faringeano curto, ca. 1/5 do corpo celular.

Hábitat: planctônico.

Entosiphon brevisiphon Skvortzov \& Noda é facilmente identificado pela forma amplamente elíptica de sua célula, pela película lisa e pelo bastonete faringeano curto, que mede ao redor de um quinto do comprimento da célula.

* E. caudatum Skvortzov \& Noda, Science Reports of Niigata University, sér. D, 7: 59, fig. 7. 1970.

Figuras 6-7

Indivíduo unicelular, solitário, livre-natante, nãometabólico; célula em forma de raquete, pólo anterior amplamente arredondado, pólo posterior prolongado em estrutura caudiforme, ca. $20 \mu \mathrm{m}$ compr., ca. $10 \mu \mathrm{m}$ larg.; seção transversal dorsiventralmente bastante comprimida, elíptica alongada, margem lisa; película extremamente delgada, lisa; flagelos 2 , de tamanhos desiguais; bastonete faringeano ca. 1/2 do corpo celular.

Hábitat: planctônico.

Skvortzov \& Noda (1970) ilustraram dois exemplares desta espécie, um dos quais (o da esquerda na figura 7) tem a forma bem próxima à de uma raquete, com o pólo posterior prolongado em uma estrutura caudiforme. O exemplar da direita é acentuadamente bilateralmente assimétrico, com a margem esquerda bastante irregular e a direita menos, porém, mais fortemente convexa nas proximidades do pólo anterior do que próximo do posterior. Outra 
diferença entre esses dois exemplares é a orientação do bastonete faringeano, que no exemplar à esquerda é paralela ao eixo longitudinal mediano e no da direita é inclinada ao mesmo eixo. Conforme nosso entender, o exemplar figurado à esquerda na ilustração original de E. caudatum Skvortzov \& Noda é o legítimo representante da espécie e o figurado à direita representaria até uma outra espécie. Contudo, por se tratar de exemplar único e ser morfologicamente tão irregular, foi nossa decisão deixá-lo de lado por enquanto, até que mais exemplares sejam coletados e avaliados.

Skvortzov \& Noda (1970) descreveram a seção celular transversal como dorsiventralmente bastante comprimida, elíptica, alongada, de margem lisa, porém, não a ilustraram.

* E. cymbellae Skvortzov \& Noda, Science Reports of Niigata University, sér. D, 6: 89, fig. 12. 1969. Figura 8

Indivíduo unicelular, solitário, livre-natante, não-metabólico; célula ovóide alongada, pólo anterior acuminado, amplamente truncado, pólo posterior amplamente arredondado, ca. $48 \mu \mathrm{m}$ compr., ca. $26 \mu \mathrm{m}$ larg.; margem lisa; película extremamente delgada, lisa; flagelos não observados; bastonete faringeano ca. 2/3 do corpo celular.

Hábitat: planctônico.

Entosiphon cymbellae Skvortzov \& Noda parece-se, quanto à forma da célula, com E. aerophyllum Skvortzov \& Noda, do qual difere, basicamente, pelo comprimento do bastonete faringeano, que no primeiro é menor do que dois terços e no segundo pouco maior do que quatro quintos do comprimento celular.

* E. dentatum Skvortzov \& Noda, Science Reports of Niigata University, sér. D, 6: 90, fig. 15. 1969. Figura 9

Indivíduo unicelular, solitário, livre-natante, nãometabólico; célula ovóide, pólo anterior acuminadotruncado, pólo posterior amplamente arredondado, 23,5-30 $\mu \mathrm{m}$ compr., 14-18 $\mu \mathrm{m}$ larg.; seção transversal dorsiventralmente pouco comprimida, amplamente elíptica, margem denteada; película extremamente delgada, longitudinalmente estriada, ca. 12 estrias ao longo da célula; flagelos 2 , anterior pouco mais curto que o corpo da célula, posterior aproximadamente tão longo quanto o corpo da célula; bastonete faringeano ca. $1 / 2$ do corpo celular.

Hábitat: planctônico.
A margem celular suave, mas nítida e irregularmente denteada, torna esta espécie única entre todas as que foram coletadas no PEFI.

Skvortzov \& Noda (1969) descreveram a existência de dois flagelos, dos quais o anterior é pouco mais curto do que o corpo da célula e o posterior á aproximadamente tão longo quanto a célula, mas, ilustrou apenas o flagelo anterior.

* E. eichhorniae Skvortzov \& Noda, Science Reports of Niigata University, sér. D, 6: 89, fig. 10. 1969. Figura 10

Indivíduo unicelular, solitário, livre-natante, nãometabólico; célula ovóide alongada, pólo anterior acuminado, pólo posterior amplamente arredondado, 16,5-21 $\mu \mathrm{m}$ compr., 11-11,6 $\mu \mathrm{m}$ larg.; margem lisa; película extremamente delgada, lisa; flagelos 2, anterior aproximadamente tão longo quanto o corpo da célula, posterior 1-1,5 vezes mais longo que o corpo da célula; bastonete faringeano curto, ca. 1/5 do corpo celular.

Hábitat: planctônico.

Entosiphon eichhorniae Skvortzov \& Noda pode ser confundido com E. fontinalis Skvortzov $\&$ Noda, porém difere na célula relativamente mais longa do que larga e no menor comprimento do bastonete faringeano, que é ao redor de um quinto do comprimento da célula.

A grafia original do epíteto desta espécie é echhorniae, que foi corrigida para eichhorniae, com a adição da letra "i" para completar a sílaba "ei" e estar conforme a grafia do nome genérico Eichhornia (aguapé), do qual deriva.

* E. ellipticum Skvortzov \& Noda, The Journal of Japanese Botany 43(6): 167, fig. 9. 1968.

Figura 11

Indivíduo unicelular, solitário, livre-natante, nãometabólico; célula oblonga, pólos anterior e posterior igual e amplamente arredondados, 15-26 $\mu \mathrm{m}$ compr., 9-16 $\mu \mathrm{m}$ larg.; seção transversal dorsiventralmente comprimida, elíptica; película extremamente delgada, lisa; flagelos 2, aproximadamente tão longos quanto o corpo da célula; bastonete faringeano ca. 1/2 do corpo celular.

Hábitat: planctônico.

Embora Skvortzov \& Noda (1968) não tivessem feito referência ao caráter liso da película dos representantes desta espécie, assim a ilustraram (Skvortzov \& Noda, 1968: fig. 9). Por outro lado, os referidos autores identificaram a seção celular 
transversal como sendo elíptica e dorsiventralmente comprimida, entretanto, não a ilustraram.

\section{* E. fontinalis Skvortzov \& Noda, Science Reports of Niigata University, sér. D, 6: 89, fig. 8. 1969.}

\section{Figura 12}

Indivíduo unicelular, solitário, livre-natante, nãometabólico; célula ovóide, pólo anterior acuminado, pólo posterior amplamente arredondado, um tanto truncado, ca. $26 \mu \mathrm{m}$ compr., ca. $22 \mu \mathrm{m}$ larg.; margem lisa; película extremamente delgada, lisa; flagelos 2 , anterior aproximadamente tão longo quanto o corpo da célula, posterior 2-2,5 vezes mais longo que o corpo da célula; bastonete faringeano situado obliquamente na célula, ca. 1/2 do corpo celular. Hábitat: planctônico.

Entosiphon fontinalis Skvortzov \& Noda pode ser confundido com E. eichhorniae Skvortzov \& Noda, porém difere na célula não tão longa quanto larga e no maior comprimento do bastonete faringeano, que é ao redor da metade do comprimento da célula.

* E. longiusculum Skvortzov \& Noda, Science Reports of Niigata University, sér. D, 7: 60, fig. 10. 1970 .

Figura 13

Indivíduo unicelular, solitário, livre-natante, não-metabólico; célula elíptica, pólos anterior e posterior igualmente acuminados, 19-30 $\mu \mathrm{m}$ compr., 9-11 $\mu \mathrm{m}$ larg.; seção transversal crenulada apenas de um lado, ca. 7 crenulações; película extremamente delgada, longitudinalmente estriada, ca. 5 estrias ao longo da célula; flagelos 2 , anterior tão longo quanto a célula, flagelo posterior ca. 2 vezes o comprimento da célula; bastonete faringeano ca. 1/4 do corpo celular.

Hábitat: planctônico.

Três espécies que ocorrem no PEFI possuem a margem da célula crenulada quando observada em seção transversal, quais sejam: E. longiusculum Skvortzov \& Noda, E. pulchrum Skvortzov \& Noda e E. stagnalis Skvortzov \& Noda. Destas, E. longiusculum Skvortzov \& Noda é a única que possui a célula elíptica, com os pólos anterior e posterior igualmente acuminados. O número de crenulações marginais contáveis na seção transversal da célula também pode ser um caráter diferencial entre essas espécies, pois E. longiusculum Skvortzov \& Noda possui sete, E. pulchrum Skvortzov \& Noda de 10 a 12 e E. stagnalis Skvortzov \& Noda cinco ou seis.

Skvortzov \& Noda (1970) identificaram a seção celular transversal desta espécie como sendo crenulada apenas de um lado, porém, não a ilustraram.

* E. longistriatum Skvortzov \& Noda, The Journal of Japanese Botany 43(6): 167, fig. 11. 1968.

Figura 14

Indivíduo unicelular, solitário, livre-natante, não-metabólico; célula oblonga, pólos anterior e posterior iguais, amplamente arredondados, 2230(-55) $\mu \mathrm{m}$ compr., 9-19(-29) $\mu \mathrm{m}$ larg.; seção transversal dorsiventralmente comprimida, elíptica, película extremamente delgada, longitudinalmente estriada, 6-7 estrias ao longo da célula; flagelos 2, aproximadamente tão longos ou pouco mais longos que o corpo da célula; bastonete faringeano ca. 1/3 do corpo celular.

Hábitat: planctônico.

* E. merdae Skvortzov \& Noda, Science Reports of Niigata University, sér. D, 7: 59, fig. 6. 1970.

Figura 15

Indivíduo unicelular, solitário, livre-natante, não-metabólico; célula obovóide alongada, um pouco assimétrica, pólo anterior amplamente arredondado, pólo posterior repentinamente acuminado, uma das margens nitidamente convexa, a outra quase reta, 15-18 $\mu \mathrm{m}$ compr., 10-11 $\mu \mathrm{m}$ larg.; seção transversal não observada; película extremamente delgada, lisa; flagelos 2, de tamanhos levemente desiguais; bastonete faringeano ca. $4 / 5$ do corpo celular.

Hábitat: planctônico.

Esta espécie foi descrita de cultivo feito pelo próprio autor a partir de esterco de cavalo, de onde deriva o epíteto específico merdae.

Embora Skvortzov \& Noda (1970) tenham descrito a forma da célula desta espécie como sendo obovóide alongada, preferimos identificá-la como oblonga ou, no máximo, subcilíndrica, com o pólo anterior menos acuminado que o posterior. Os referidos autores ilustraram uma vista que tanto pode ser a transversal quanto a longitudinal de uma célula, mas não a incluíram na descrição que fizeram da espécie. Ao que parece, esta vista não está na mesma escala da frontal, pois é um pouco mais longa do que a transversal e um pouco mais curta do que a longitudinal.

* E. nasutum Skvortzov \& Noda var. nasutum, Science Reports of Niigata University, sér. D, 7: 59, fig. 1. 1970.

Figura 16 
Indivíduo unicelular, solitário, livre-natante, não-metabólico; célula obovóide alongada, pólo anterior dilatado, com uma projeção mamilóide, pólo posterior acuminado-arredondado, ca. $15 \mu \mathrm{m}$ compr., ca. 8,5 $\mu \mathrm{m}$ larg.; seção transversal dorsiventralmente comprimida; película extremamente delgada, lisa; flagelos 2, praticamente iguais; bastonete faringeano ca. $1 / 3$ do corpo celular.

Hábitat: planctônico.

Skvortzov \& Noda (1970) descreveram do estudo de material coletado na represa Billings, Município de São Paulo, e propuzeram E. nasutum Skvortzov \& Noda var. acutum Skvortzov \& Noda, que difere da variedade-tipo da mesma espécie por apresentar a célula relativamente mais estreita, o pólo posterior mais acentuadamente acuminado e a célula duas vezes mais longa do que larga. O exame dos exemplares de cada variedade taxonômica ilustrados em Skvortzov \& Noda (1970) até justifica a proposta da var. acutum em pauta, entretanto, tal proposição pode e deve cair por terra se mais exemplares forem examinados.

Skvortzov \& Noda (1970) referem-se, na descrição da espécie, a flagelos (no plural!) quase idênticos entre si, muito provavelmente comparando-os quanto ao tamanho, mas, ilustraram apenas um deles.

* E. pluvialis Skvortzov \& Noda, Science Reports of Niigata University, sér. D, 7: 59, fig. 4. 1970. Figura 17

Indivíduo unicelular, solitário, livre-natante, nãometabólico; célula mais ou menos obovóide, ambos os pólos acuminado-arredondados ou pólo anterior amplamente arredondado, pólo posterior acuminado, 12-18 $\mu \mathrm{m}$ compr., 9,2-10,8 $\mu \mathrm{m}$ larg.; seção transversal dorsiventralmente bastante comprimida, oblonga alongada, margem lisa; película extremamente delgada, lisa; flagelos 2, anterior tão longo quanto a célula, flagelo posterior ca. 1,5 vez o comprimento da célula; bastonete faringeano ca. 1/2 do corpo celular. Hábitat: planctônico.

O formato mais ou menos obovóide da célula e a película lisa são as características diagnósticas de E. pluvialis Skvortzov \& Noda. Skvortzov \& Noda (1970) não informaram sobre o material utilizado para a proposição da espécie. Contudo, dado os autores seguirem a ordem das amostras na apresentação das diferentes espécies no texto, subentende-se que E. pluvialis Skvortzov \& Noda foi coletada de uma depressão cheia de água de chuva e folhas em decomposição no PEFI.
* E. pulchrum Skvortzov \& Noda, Science Reports of Niigata University, sér. D, 7: 60, fig. 11. 1970. Figura 18

Indivíduo unicelular, solitário, livre-natante, não-metabólico; célula subfusiforme, pólo anterior arredondado-truncado, pólo posterior acuminado, ca. 22,5 $\mu \mathrm{m}$ compr., ca. $11 \mu \mathrm{m}$ larg.; seção transversal dorsiventralmente comprimida, oblonga, margem crenulada, 9-12 crenulações em toda periferia; película extremamente delgada, longitudinalmente estriada, ca. 4 estrias ao longo da célula; flagelos 2 , de tamanhos desiguais; bastonete faringeano ca. 4/5 do corpo celular.

Hábitat: planctônico.

Skvortzov \& Noda (1970) descreveram originalmente a espécie com dois flagelos, porém, na ilustração original que faz parte do protólogo da espécie registraram apenas um.

Entosiphon pulchrum Skvortzov \& Noda é, das três espécies que ocorrem no PEFI e possuem a margem da célula crenulada quando observada em seção transversal, a única cuja célula é subfusiforme e tem o pólo anterior arredondado-truncado e o pólo posterior acuminado. O número de crenulações marginais contáveis na seção transversal da célula também pode ser um caráter diferencial entre essas três espécies, pois E. pulchrum Skvortzov \& Noda possui de 10 a 12, E. longiusculum Skvortzov \& Noda sete e E. stagnalis Skvortzov \& Noda cinco ou seis.

* E. sampaulense Skvortzov \& Noda, The Journal of Japanese Botany 43(6): 165, fig. 2-3. 1968. Figura 19

Indivíduo unicelular, solitário, livre-natante, não metabólico; célula amplamente elipsóide a quase esférica, pólos anterior e posterior amplamente arredondados, em vista lateral fortemente comprimida, 15-18(-55) $\mu \mathrm{m}$ compr., 10-15(-48) $\mu \mathrm{m}$ larg.; flagelos não mencionados; película extremamente delgada, estriada, 10-20 estrias visíveis.

Hábitat: planctônico.

Faz-se, presentemente, a correção do epíteto específico de saopaulensis para sampaulense.

Skvortzov \& Noda (1968) ilustraram a presença de dois flagelos (veja fig. 19), sendo o anterior mais curto e o posterior aproximadamente tão longo quanto o corpo da célula. Contudo, deixaram de incluir tal informação na descrição original da espécie.

* E. skvortzovii C. Bicudo, sp. nov.

Figura 38 


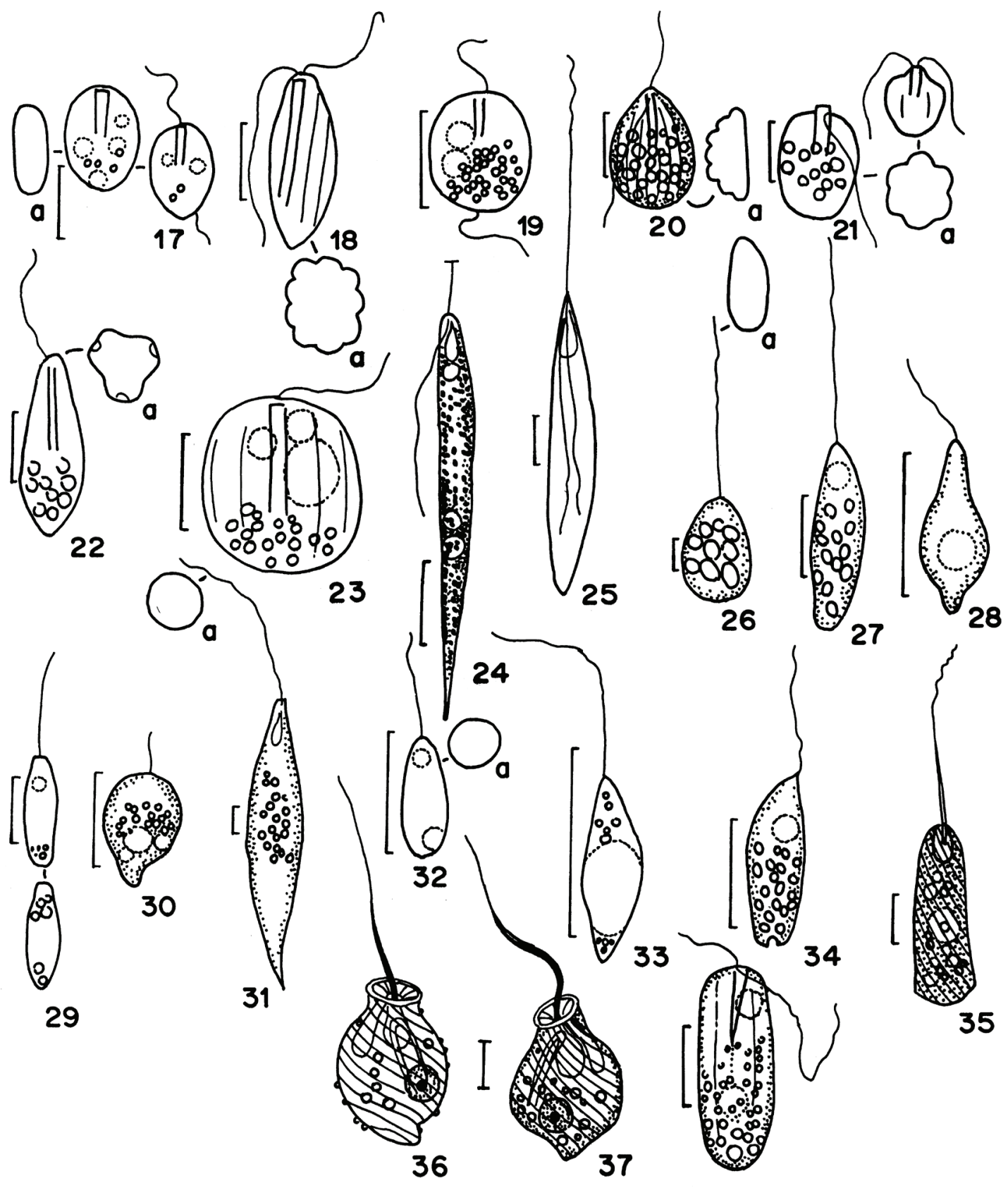

Figuras 17-36. Espécies de Paranemaceae do Parque Estadual das Fontes do Ipiranga. 17. Entosiphon pluvialis (Skvortzov \& Noda 1970). 18. E. pulchrum (Skvortzov \& Noda 1970). 19. E. sampaulense (Skvortzov \& Noda 1968). 20. E. spiralis (Skvortzov \& Noda 1970). 21. E. stagnalis (Skvortzov \& Noda 1969). 22. E. triquetrum (Skvortzov \& Noda 1969). 23. E. utriculariae (Skvortzov \& Noda 1968). 24. Heteronema aquae-purae (Skvortzov 1966). 25. H. palmeri (Skvortzov 1966). 26. Parmidium sampaulense (Skvortzov 1966$) .27$. P. cyanophorum (Skvortzov 1969). 28. P. nasutum (Skvortzov 1969). 29. P. obliquum (Skvortzov 1967). 30. P. obovatum (Skvortzov 1969). 31. P. saprophyticum (Skvortzov 1969). 32. P. simplicium (Skvortzov 1967). 33. P. subnasutum (Skvortzov 1967). 34. P. terrestre (Skvortzov 1969). 35. Peranema inflexum (Bicudo \& Bicudo 1970). 36-37. Urceolus cyclostomus (Menezes 1993). 38. E. skvortzovii sp. nov. (Skvortzov \& Noda 1969). Barras das escalas $=10 \mu \mathrm{m}$.

Figures 17-36. Species of Paranemaceae from the "Parque Estadual das Fontes do Ipiranga". 17. Entosiphon pluvialis (Skvortzov \& Noda 1970). 18. E. pulchrum (Skvortzov \& Noda 1970). 19. E. sampaulense (Skvortzov \& Noda 1968). 20. E. spiralis (Skvortzov \& Noda 1970). 21. E. stagnalis (Skvortzov \& Noda 1969). 22. E. triquetrum (Skvortzov \& Noda 1969). 23. E. utriculariae (Skvortzov \& Noda 1968). 24. Heteronema aquae-purae (Skvortzov 1966). 25. H. palmeri (Skvortzov 1966). 26. Parmidium sampaulense (Skvortzov 1966). 27. P. cyanophorum (Skvortzov 1969). 28. P. nasutum (Skvortzov 1969). 29. P. obliquum (Skvortzov 1967). 30. P. obovatum (Skvortzov 1969). 31. P. saprophyticum (Skvortzov 1969). 32. P. simplicium (Skvortzov 1967). 33. P. subnasutum (Skvortzov 1967). 34. P. terrestre (Skvortzov 1969). 35. Peranema inflexum (Bicudo \& Bicudo 1970). 36-37. Urceolus cyclostomus (Menezes 1993). 38. E. skvortzovii sp. nov. (Skvortzov \& Noda 1969). Scale bars $=10 \mu \mathrm{m}$. 
Individuum unicellulare, solitarium, natans, non-metabolicum; cellula oblonga, polo anteriori rotundato-truncato, polo posteriori ample rotundato, ca. 22 um longo, 7-9 $\mu \mathrm{m}$ lato, margo laevis; pellicula maxime tenuis, longitudinaliter striata. 6-8 striis secundum cellulam; flagella 2, fere longiora quam corpus cellulae; bacillus pharynxianus triangulariinversus, extremitate acuminata, ca. 2/5 longitudinem cellulae occupans.

Typus: Skvortzov \& Noda (1969: fig. 6, ut E. utriculariae Skvortzov \& Noda).

Indivíduo unicelular, solitário, livre-natante, nãometabólico; célula oblonga, pólo anterior arredondado truncado, pólo posterior amplamente arredondado, ca. $22 \mu \mathrm{m}$ compr., 7-9 $\mu \mathrm{m}$ larg., margem lisa; película extremamente delgada, longitudinalmente estriada, 6-8 estrias ao longo da célula; flagelos 2, aproximadamente tão longos ou pouco mais longos que o corpo da célula; bastonete faringeano triangularinvertido, extremidade acuminada, ocupando ca. dois quintos do comprimento da célula.

Tipo: Skvortzov \& Noda (1969: fig. 6, como E. utriculariae Skvortzov \& Noda).

Hábitat: planctônico.

Skvortzov \& Noda (1969: 89, fig. 6) propuseram a nova espécie E. utriculariae Skvortzov \& Noda a partir de material coletado de um ambiente permanente, de água estagnada, situado no Parque Estadual das Fontes do Ipiranga, porém, sem identificar exatamente o local. Um ano antes, entretanto, os mesmos autores (Skvortzov \& Noda 1968: 167, fig. 7) haviam descrito outra espécie de Entosiphon, com esse mesmo nome (E. utriculariae Skvortzov \& Noda), porém, morfologicamente bem diferente. A célula do material em Skvortzov \& Noda (1968) varia desde subcircular até amplamente oblonga, com os pólos anterior e posterior iguais entre si e amplamente arredondados, medindo 19-29 $\mu \mathrm{m}$ compr. e 15-17 $\mu \mathrm{m}$ larg. O bastonete faringeano é cilíndrico e ocupa ca. dois terços do comprimento da célula. A película é longitudinalmente estriada, com ca. 8 estrias por célula. Embora os materiais em Skvortzov \& Noda (1968) e Skvortzov \& Noda (1969) sejam bastante distintos um do outro, do ponto de vista nomenclatural o segundo é um homônimo posterior ilegítimo de Entosiphon utriculariae em Skvortzov \& Noda (1968) e tem, portanto, que ser rejeitado conforme o Art. 53.1 do Código Internacional de Nomenclatura Botânica (McNeill et al. 2006).

Nesta circunstância, concordando tratar de uma espécie nova para a Ciência, descrevemos formalmente o material original e o nomeamos em homenagem ao Prof. Boris Vassilievich Skvortzov, quem trabalhou no Instituto de Botânica por vários anos e coletou e estudou o material que serviu de base para a materialização do trabalho Skvortzov \& Noda (1969).

A eleição de uma ilustração para ser o tipo nomenclatural da espécie está baseada no art. 37.5 do Código Internacional de Nomenclatura Botânica (McNeill et al. 2006).

* E. spiralis Skvortzov \& Noda, Science Reports of Niigata University, sér. D, 6: 90, fig. 14. 1970.

Figura 20

Indivíduo unicelular, solitário, livre-natante, não-metabólico; célula ovóide, pólo anterior acuminado, pólo posterior amplamente arredondado, ca. $30 \mu \mathrm{m}$ compr., ca. 22,5 $\mu \mathrm{m}$ larg.; seção transversal assimétrica, mais ou menos semicircular, margem convexa crenulada, ca. 7 crenulações, margem reta lisa; película extremamente delgada, longitudinalmente estriada, ca. 12 estrias ao longo da célula; flagelos 2 , de tamanhos desiguais; bastonete faringeano ca. $1 / 2$ do corpo celular.

Hábitat: planctônico.

Entosiphon spiralis Skvortzov \& Noda pode ser facilmente identificada pela seção transversal assimétrica de sua célula, mais ou menos semicircular, onde a margem convexa é crenulada, com cerca de sete crenulações e a margem reta é lisa

* E. stagnalis Skvortzov \& Noda, Science Reports of Niigata University, sér. D, 7: 60, fig. 14. 1969. Figura 21

Indivíduo unicelular, solitário, livre-natante, não-metabólico; célula oblonga a curto-cilíndrica, pólos anterior e posterior amplamente arredondadotruncados, ca. $26 \mu \mathrm{m}$ compr., ca. $15 \mu \mathrm{m}$ larg.; seção transversal dorsiventralmente pouco comprimida, subcircular, margem crenulada, 5-6 crenulações em toda periferia; película extremamente delgada, lisa; flagelos 2, anterior tão longo quanto a célula, flagelo posterior ca. 1,5 vez o comprimento da célula; bastonete faringeano projetado além do pólo anterior da célula, ca. 1/2 do corpo celular.

Hábitat: planctônico.

As três espécies seguintes que ocorrem no PEFI possuem a margem da célula crenulada quando observada em seção transversal: E. longiusculum Skvortzov \& Noda, E. pulchrum Skvortzov \& Noda e E. stagnalis Skvortzov \& Noda. Destas, E. 
stagnalis Skvortzov \& Noda é a única que possui a célula oblonga a curto-cilíndrica, com os pólos anterior e posterior amplamente arredondado-truncados. O número de crenulações marginais contadas na seção transversal da célula também pode auxiliar na diferenciação entre essas espécies, pois E. stagnalis Skvortzov \& Noda cinco ou seis crenulações, $E$. longiusculum Skvortzov \& Noda sete e E. pulchrum Skvortzov \& Noda entre 10 e 12.

* E. triquetrum Skvortzov \& Noda, Science Reports of Niigata University, sér. D, 7: 60, fig. 12. 1969. Figura 22

Indivíduo unicelular, solitário, livre-natante, não-metabólico; célula obovóide alongada, pólo anterior arredondado-truncado em bisel, pólo posterior gradualmente acuminado, ca. $18 \mu \mathrm{m}$ compr., ca. $6 \mu \mathrm{m}$ larg.; seção transversal 3-angular, ângulos arredondadotruncados, margem entre ângulos côncava, lisa; película extremamente delgada, longitudinalmente estriada, estrias indistintas; flagelos 2, anterior tão longo quanto a célula, flagelo posterior não observado; bastonete faringeano ca. 1/2 do corpo celular.

Hábitat: planctônico.

A espécie é única pela seção transversal triangular.

* E. utriculariae Skvortzov \& Noda, The Journal of Japanese Botany 43(6): 167, fig. 7. 1968.

Figura 23

Indivíduo unicelular, solitário, livre-natante, não-metabólico; célula subcircular a amplamente oblonga, pólos anterior e posterior iguais, amplamente arredondados, 19-29 $\mu$ m compr., 15-17 $\mu$ m larg.; seção transversal dorsiventralmente comprimida, elíptica; película extremamente delgada, longitudinalmente estriada, ca. 8 estrias ao longo da célula; flagelos 2 , pouco mais curtos que o corpo da célula; bastonete faringeano ca. $2 / 3$ do corpo celular.

Hábitat: planctônico.

Skvortzov \& Noda (1969: 89, fig. 6) propuseram uma nova espécie que nomearam E. utriculariae, porém, completamente diferente de E. utriculariae em Skvortzov \& Noda (1968: 167. fig. 7). A célula do material em Skvortzov \& Noda (1969) é cilíndrica, com o pólo anterior arredondado-truncado e o posterior amplamente arredondado, medindo $22 \mu \mathrm{m}$ compr. e 7-9 $\mu \mathrm{m}$ larg., com bastonete faringeano triangularinvertido, de extremidade acuminada, ocupando ca. dois quintos do comprimento da célula, com a película longitudinalmente estriada e 6-8 estrias por célula. Embora um organismo bastante distinto daquele descrito anteriormente com o mesmo nome, do ponto de vista nomenclatural Entosiphon utriculariae em Skvortzov \& Noda (1969) é um homônimo posterior ilegítimo de Entosiphon utriculariae em Skvortzov \& Noda (1968) e deve, portanto, ser rejeitado conforme o Art. 53.1 do Código Internacional de Nomenclatura Botânica (McNeill et al. 2006).

Skvortzov \& Noda (1969) identificaram a seção celular transversal como sendo dorsiventralmente comprimida e elíptica e a existência de oito estrias ao longo da célula. Contudo, não ilustraram nem a seção transversal da célula nem as estrias da película.

Heteronema Dujardin emend. Stein

Indivíduos unicelulares acentuadamente metabólicos, de vida livre e hábito solitário. A célula é heteropolar quando totalmente distendida, ou seja, apresenta o pólo anterior em geral amplamente arredondado e o posterior acuminado; todavia, o pólo anterior também pode ser acuminado-arredondado e o posterior amplamente arredondado. A película é extremamente delgada e pode ser lisa ou estriada helicoidalmente. Os dois flagelos inserem-se anterior e subapicalmente na célula e têm tamanhos desiguais entre si, sendo o maior dos dois de fácil visualização, pois é mais espesso, reto ou quase e está sempre dirigido para frente e o menor é mais delicado e vai estirado frontalmente enquanto a célula se move, sempre colado ao corpo da célula. Uma característica dos representantes deste gênero é o bastonete faringeano, isto é, um tipo de tubo longo e mais ou menos cônico associado ao citóstoma e que faz parte do sistema paravestibular. A função do bastonete faringeano ainda permanece desconhecida.

A localização do bastonete faringeano associado ao citóstoma em Heteronema mantém este gênero independente de Peranema, cujo bastonete está situado adjacente ao reservatório, não associado ao citóstoma. Além disso, o flagelo menor de Peranema é de difícil vizualização, pois se encontra intimamente colado à superfície da célula e, em geral, no interior de um canal.

Chave para as espécies de Heteronema

1. Pólo posterior da célula fortemente acuminado, pontiagudo ..................................... * H. palmeri 1. Pólo posterior da célula amplamente arredondado *H. acquae-purae

*H. aquae-purae Skvortzov, Quarterly Journal of the Taiwan Museum 19(1-2): 148, fig. 19-20. 1966. Figura 24 
Indivíduo unicelular, solitário, livre-natante, altamente metabólico; célula subfusiforme, pólo anterior amplamente arredondado, pólo posterior amplamente arredondado, 18-30 $\mu \mathrm{m}$ compr., 8-25 $\mu \mathrm{m}$ larg.; seção transversal mais ou menos circular; película extremamente delgada, lisa; flagelos 2 , anterior $1 / 2$ $2 / 3$ do comprimento da célula, flagelo posterior ca. $1 / 2$ do comprimento da célula; bastonete faringeano não observado; grânulos de paramido elípticos, vários, esparsos pela célula.

Hábitat: planctônico.

Skvortzov (1966) indicou, na legenda de sua prancha de ilustrações, as fig. 16-18 como representantes desta espécie, porém, no texto referiu as fig. 19-20. Com base na descrição da espécie, estas últimas são, de fato, as ilustrações corretas de $H$. aquae-purae Skvortzov.

O referido autor mencionou a presença de um ou vários vacúolos digestivos nas células de $H$. aquae-purae Skvortzov, contendo restos de células de Cosmarium, Mesotaenium, Chlamydomonas e de criptofíceas (Skvortzov 1966).

Skvortzov (1966) identificou a seção celular transversal como sendo mais ou menos circular e a existência de vários grânulos de paramido esparsos pela célula. Mas, não ilustrou nem uma nem a outra característica.

* H. palmeri Skvortzov, Quarterly Journal of the Taiwan Museum 19(1-2): 147, fig. 15. 1966.

Figura 25

Indivíduo unicelular, solitário, livre-natante, altamente metabólico; célula fusiforme, pólo anterior acuminado-arredondado, pólo posterior fortemente acuminado, pontiagudo, ca. $37 \mu \mathrm{m}$ compr., 12-14 $\mu \mathrm{m}$ larg.; seção transversal não referida; película extremamente delgada, lisa; flagelos 2 , anterior ca. $2 / 3$ do comprimento da célula, flagelo posterior ca. $2 / 3$ do comprimento da célula; bastonete faringeano não observado; grânulos de paramido não observados.

Hábitat: planctônico.

Os espécimes examinados por Skvortzov (1966) foram coletados do líquido resultante do espremido de plantas de Salvinia auriculata Aublet e, em seguida, cultivados em laboratório pelo próprio autor.

Parmidium Christen $=$ Menoidiomonas Skvortzov $1958 \equiv$ Huberpestalozziamonas Skvortzov 1967 =Mariniamonas Skvortzov 1969 三 Hoehnemonas Skvortzov $1969 \equiv$ Bicudomonas Skvortzov 1969 三 Liangiana Skvortzov 1969 三Nilzamonas Skvortzov 1969

Indivíduos unicelulares livre-natantes, desde extremamente até não-metabólicos e de hábito isolado. A forma da célula em repouso varia entre esférica, elipsoidal, ovóide ou fusiforme, porém, a seção transversal pode ser achatada, com uma das faces convexa e a oposta côncava ou perfeitamente circular. A película é extremamente delgada e lisa ou estriada. O protoplasma pode apresentar cianelas (endossimbiontes). Existem vários grãos de paramido elipsóides ou globosos situados, principalmente, na região anterior da célula. Estigma ausente. O flagelo é único e situa-se apicalmente na célula, dirigido para frente, inflexível em sua maior parte (só a extremidade vibra) e é, em geral, aproximadamente tão longo quanto o corpo da célula (em $P$. sampaulense mede 1,5-2 vezes o comprimento do corpo da célula). Os gêneros Eneidamonas Skvortzov e Mariniamonas Skvortzov foram considerados por Bourrelly (1970) sinônimos de Parmidium Christen, atitude esta endossada por Bicudo \& Menezes (2006). Atualmente, entretanto, dada a pouca informação disponível sobre Eneidamonas, optou-se por mantê-la entre os materiais que não dispõem de informação suficiente tanto na descrição quanto na ilustração original, que possibilitem avaliar criticamente o material em Skvortzov (1969).

Os representantes dos gêneros Acusmonas Skvortzov, Bicudomonas Skvortzov, Calawaymonas Skvortzov, Hoehnemonas Skvortzov, Liangiana Skvortzov, Mariniamonas Skvortzov, Menoidiomonas Skvortzov, Nilzamonas Skvortzov, Skujamonas Skvortzov e Wellsiella Skvortzov diferem muito pouco entre si e dos espécimes de Parmidium Christen devendo, portanto, ser considerados todos sinônimos deste último.

1. Cianelas presentes * P. cyanophorum

1. Cianelas ausentes

2. Reservatório presente * P. saprophyticum 
2. Reservatório ausente

3. Célula achatada frontalmente, seção transversal elíptica

*P. obliquum

3. Célula não achatada frontalmente, seção transversal circular ou quase

4. Célula clavada, ovóide a ovóide alongada

5. Célula clavada, extremamente metabólica *P. obovatum

5. Célula ovóide a ovóide alongada

6. Célula 1,5-1,6 vezes mais longa que larga *P. simplicium

6. Célula ca. 3,3 vezes mais longa que larga

* P. sampaulense

4. Célula subfusiforme, fusiforme-alongada ou piriforme.

7. Indivíduo não metabólico

*P. subnasutum

7. Indivíduo extremamente metabólico

8. Célula subfusiforme, pólo anterior acuminado, pólo posterior arredondado-truncado

* P. terrestre

8. Célula aproximadamente piriforme, pólo anterior arredondado, pólo posterior amplamente arredondado ou mamilado

* P. nasutum

* P. cyanophorum (Skvortzov) C. Bicudo, comb. nov. (= Bicudomonas cyanophora Skvortzov, Quarterly Journal of the Taiwan Museum 22: 226, fig. 2. 1969).

\section{Figura 27}

Indivíduo unicelular, solitário, livre-natante, extremamente metabólico; célula em repouso subfusiforme, pólo anterior acuminado, pólo posterior arredondado-truncado, 22-24 $\mu \mathrm{m}$ compr., 6-8 $\mu \mathrm{m}$ larg.; película extremamente delgada, lisa; flagelo único, reto, estirado para a frente, aproximadamente tão longo quanto o corpo da célula; cianelas azulesverdeadas, várias, distribuídas do reservatório para o pólo posterior.

Hábitat: planctônico.

A célula subfusiforme quando em repouso, com o pólo anterior acuminado e o posterior arredondadotruncado identifica esta espécie. Há dúvida se os corpúsculos azul-esverdeados espalhados no citoplasma da célula são, de fato, cianelas ou um artefato de técnica ou um erro de interpretação.

* P. nasutum (Skvortzov) C. Bicudo, comb. nov. (= Hoehnemonas nasuta Skvortzov, Quarterly Journal of the Taiwan Museum 22: 229, fig. 9. 1969).

\section{Figura 28}

Indivíduo unicelular, solitário, livre-natante, extremamente metabólico principalmente na porção posterior; célula em repouso aproximadamente piriforme, pólo anterior arredondado, pólo posterior amplamente arredondado ou mamilado, 10-15 $\mu \mathrm{m}$ compr., 5,2-7,8 $\mu \mathrm{m}$ larg.; película extremamente delgada, lisa; flagelo único, aproximadamente tão longo quanto o corpo da célula.
Hábitat: planctônico.

Parmidium nasutum (Skvortzov) C. Bicudo é característica pela célula piriforme quando em repouso, com o pólo anterior arredondado e o posterior amplamente arredondado ou mamilado.

* P. obliquum (Skvortzov) C. Bicudo, comb. nov. (= Huberpestalozziamonas obliqua Skvortzov, The Bulletin of Japanese Society of Phycology 15(2): 78, fig. 2, 4. 1967).

Figura 29

Indivíduo unicelular, solitário, livre-natante, nãometabólico; célula em repouso fusiforme-alongada, reta ou pouco curvada, pólo anterior amplamente truncado, pólo posterior gradual ou repentinamente afilado, ápice acuminado-arredondado, 15-18,5 $\mu \mathrm{m}$ compr., 5-9 $\mu \mathrm{m}$ larg.; seção transversal frontalmente comprimida, elíptica; película extremamente delgada, lisa; flagelo único, aproximadamente tão longo quanto o corpo da célula; reservatório indistinto.

Hábitat: planctônico.

* P. obovatum (Skvortzov) C. Bicudo, comb. nov. (= Hoehnemonas obovata Skvortzov, Quarterly Journal of the Taiwan Museum 22: 229, fig. 31. 1969). Figura 30

Indivíduo unicelular, solitário, livre-natante, extremamente metabólico principalmente na porção posterior; célula em repouso clavada, pólo anterior amplamente arredondado, pólo posterior abruptamente diferenciado do corpo da célula, arredondado, 10-14 $\mu \mathrm{m}$ compr., 6,5-9,7 $\mu \mathrm{m}$ larg.; película extremamente delgada, lisa; flagelo único, aproximadamente tão longo quanto o corpo da célula. Hábitat: planctônico. 
A espécie é facilmente identificada pela célula em repouso obovóide, em que o pólo anterior é amplamente arredondado e o posterior abruptamente diferenciado do corpo da célula, porém, de extremidade arredondada.

* P. sampaulense (Skvortzov) C. Bicudo (= Mariniamonas saupaulensis Skvortzov, Quarterly Journal of the Taiwan Museum 22: 226, fig. 1. 1969).

Figura 26

Indivíduo unicelular, solitário, livre-natante, nãometabólico; célula em repouso ovóide, pólo anterior acuminado-arredondado, pólo posterior amplamente arredondado, frontalmente achatada, 10-12 $\mu \mathrm{m}$ compr., 6,4-7,7 $\mu \mathrm{m}$ larg.; película extremamente delgada, lisa; flagelo único, 2 vezes mais longo que o corpo da célula; estigma punctiforme, próximo ao pólo anterior; grãos de paramido 5-7, mais ou menos baciliformes, grandes, distribuídos por toda a célula. Hábitat: planctônico.

A grafia original do epíteto específico em Skvortzov (1969) é saupaulensis, atualmente corrigida para sampaulense.

Skvortzov (1969: fig. 1) ilustrou apenas um espécime de Mariniamonas saupaulensis Skvortzov [= Parmidium sampaulense (Skvortzov) C. Bicudo], o qual mostra só palidamente o estigma, próximo do pólo anterior, quase colado na margem esquerda da célula.

* P. saprophyticum (Skvortzov) C. Bicudo, comb. nov. (= Nilzamonas saprophyticum Skvortzov, Quarterly Journal of the Taiwan Museum 22: 231, fig. 13. 1969).

\section{Figura 31}

Indivíduo unicelular, solitário, livre-natante, não-metabólico; célula em repouso fusiforme, pólo anterior amplamente truncado, pólo posterior afilado gradualmente, ápice acuminado, 45-65 $\mu \mathrm{m}$ compr., 8,5-12,3 $\mu \mathrm{m}$ larg.; seção transversal circular ou quase; película extremamente delgada, lisa; flagelo único, voltado para frente, aproximadamente tão longo quanto o corpo da célula; grãos de paramido vários, baciliformes, distribuídos na porção mediana da célula.

Hábitat: planctônico.

Parmidium saprophyticum (Skvortzov) C. Bicudo foi observado de material em cultivo de esterco eqüino coletado por B.V. Skvortzov no PEFI. Foram cultivos temporários feitos apenas com água de torneira e o esterco, que foram logo descartados pelo autor. Não há, pois, documentação deste material no herbário do Instituto de Botânica.

* P. simplicium (Skvortzov) C. Bicudo, comb. nov. (= Huberpestalozziamonas simplicia Skvortzov, The Bulletin of Japanese Society of Phycology 15(2): 78, fig. 12. 1967).

Figura 32

Indivíduo unicelular, solitário, livre-natante, não-metabólico; célula em repouso ovóide-alongada, pólo anterior arredondado-acuminado, pólo posterior amplamente arredondado, ca. 10 compr., ca. 3 $\mu \mathrm{m}$ larg.; seção transversal praticamente circular; película extremamente delgada, lisa; flagelo único, aproximadamente tão longo quanto o corpo da célula; reservatório indistinto.

Hábitat: planctônico.

* P. subnasutum (Skvortzov) C. Bicudo, comb. nov. (= Huberpestalozziamonas subnasuta Skvortzov, The Bulletin of Japanese Society of Phycology 15(2): 77, fig. 1, 3. 1967).

Figura 33

Indivíduo unicelular, solitário, livre-natante, não-metabólico; célula em repouso fusiformealongada, reta, pólo anterior abruptamente afilado, obliquamente truncado, pólo posterior abruptamente afilado, ápice arredondado a acuminado-arredondado, 15-18,5 $\mu \mathrm{m}$ compr., 5-7,4 $\mu \mathrm{m}$ larg.; seção transversal circular ou quase; película extremamente delgada, lisa; flagelo único, aproximadamente tão longo ou pouco mais longo que o corpo da célula; reservatório indistinto; grãos de paramido vários, pequenos, globosos, situados nos pólos anterior e posterior da célula.

Hábitat: planctônico.

* P. terrestre (Skvortzov) C. Bicudo, comb. nov. (= Liangiana terrestris Skvortzov, Quarterly Journal of the Taiwan Museum 22: 227, fig. 4. 1969).

Figura 34

Indivíduo unicelular, solitário, livre-natante, extremamente metabólico principalmente na porção posterior; célula em repouso subfusiforme, pólo anterior acuminado, pólo posterior arredondadotruncado, 18-25 $\mu \mathrm{m}$ compr., 6-8,3 $\mu \mathrm{m}$ larg.; película extremamente delgada, lisa; flagelo único, aproximadamente tão longo quanto o corpo da célula; grãos de paramido numerosos, esféricos na parte anterior, baciliformes na parte posterior da célula. Hábitat: planctônico. 
Skvortzov (1969) refere-se a grãos de paramido esféricos na parte anterior da célula e baciliformes na parte posterior, porém, ilustra apenas baciliformes na parte posterior da célula.

O exemplar ilustrado por Skvortzov (1969) apresenta o que parece ser um citopígeo, o qual foi referido pelo dito autor como citoprocto e definido como uma característica diagnóstica ou, pelo menos, descritiva do gênero Liangiana.

\section{Peranema Dujardin}

Indivíduos unicelulares, despigmentados, acentuadamente metabólicos, livre-natantes e de hábito isolado. A forma da célula totalmente distendida é bipolar, isto é, apresenta o pólo anterior subagudo e o posterior amplamente arredondado. Ocorrem dois flagelos de tamanhos bastante diferentes, sendo que o maior deles é de fácil visualização por ser mais espesso e aparecer reto ou quase, dirigido para frente enquanto a célula se desloca; apenas sua extremidade distal vibra. O flagelo menor é recorrente e localiza-se no interior de um sulco longitudinal que tem origem na abertura da citofaringe. Por conta de sua situação, este flagelo passa, quase sempre, despercebido. A película é muito delgada e estriada helicoidalmente.

Suspeita-se que o gênero Heteronema Dujardin emend. Stein seja sinônimo de Peranema, pois inclui os indivíduos metabólicos que apresentam um flagelo anterior bastante conspícuo. Contudo, tal circunscrição abrange também os indivíduos de Anisonema Dujardin e Refractomonas Skvortzov \& Noda, que deverão ser considerados na eventualidade da sinonímia com Heteronema ser efetivada.

A única referência à ocorrência deste gênero no Brasil está em Bicudo \& Bicudo (1970), que identificaram Peranema sp. de material do hidrofitotério, situado no Jardim Botânico de São Paulo.

Só uma espécie foi identificada.

\section{P. inflexum Skuja, Acta Horti Botanici Universitatis} Latviensis 11-12: 143, pl. 7, fig. 33-35. 1939.

\section{Figura 35}

Indivíduo unicelular, solitário, livre-natante, bastante metabólico; célula em repouso cuneiforme, pólo anterior acuminado-arredondado, pólo posterior amplamente truncado-arredondado, 35-54,3 $\mu \mathrm{m}$ compr., 9,8-12,4 $\mu \mathrm{m}$ larg.; película extremamente delgada, estriada helicoidalmente; flagelo único, aproximadamente tão longo quanto o corpo da célula. Hábitat: planctônico.
Skuja (1939) descreveu a célula mais ou menos arqueada, raro reta. Todos os indivíduos ora observados apresentaram-se retos. Exceto esta diferença, as demais características do material do PEFI coincidem com a circunscrição de $P$. inflexum Skuja.

\section{Urceolus Mereschkowski}

Indivíduos unicelulares ativamente móveis, nãometabólicos e de hábito isolado. A forma da célula em repouso pode ser elipsóide ou piriforme, sempre com uma depressão na região anterior circundada por um colarinho em forma de funil. A película é estriada e as estrias são helicoidais e espessas. Algumas vezes, podem ocorrer grânulos inorgânicos aderidos à película. $\mathrm{O}$ flagelo é único, grosseiro e apresenta-se reto, direcionado para frente durante a natação e situase subapicalmente na célula. $\mathrm{O}$ bastonete faringeano é, em geral, bem evidente. O gênero é constituído por indivíduos que se nutrem por processo fagotrófico.

Uma única espécie foi identificada.

* U. cyclostomus (Stein) Mereschkowski, Annals and Magazine of Natural History: ser. 5, 7: 219. 1881 $\equiv$ Phialonema cyclostomus Stein, Der Organismus Infusionsthiere 3: pl. 23, fig. 42-48. 1878.

Figuras 36-37

Indivíduo unicelular, solitário, livre-natante, não-metabólico; célula em repouso mais ou menos urceolada, bilateralmente assimétrica, pólo anterior obliquamente truncado, formando um colar em torno do flagelo, margens laterais desigualmente convexas, pólo posterior abruptamente afilado, acuminadoarredondado, seção transversal não observada, 31-42 $\mu \mathrm{m}$ compr., 20,4-29 $\mu \mathrm{m}$ larg.; colar mais ou menos acentuadamente oblíquo, divergente para o ápice, 3,2$6 \mu \mathrm{m}$ alt., 9-12 $\mu \mathrm{m}$ larg. na abertura, película delgada, helicoidalmente estriada, às vezes com partículas do meio aderidas; flagelo único, ca. 1,5 vez mais longo que o corpo da célula; estigma ausente; grãos de paramido numerosos, mais ou menos globóides, pequenos, distribuídos por toda a célula; bastonetes faringeanos 2, ca. metade do corpo celular.

Hábitat: planctônico.

Todo o conhecimento desta espécie no Brasil consta em Menezes (1993), que a identificou de sedimentos provenientes de uma lagoa no Bosque da Barra, uma área de preservação situada na Barra da Tijuca, região oeste da cidade do Rio de Janeiro. Esta é a segunda notícia da ocorrência de Urceolus cyclostomum (Stein) Mereschkowski no país. 
Stein (1878) não descreveu formalmente Phialonema cyclostomus Stein, ou seja, o basiônimo de Urceolus cyclostomum (Stein) Mereschkowski. As ilustrações que forneceu (Stein 1878: pl. 23, fig. 42-48) representam, ao que tudo indica, duas ou três espécies distintas. Contudo, Stein (1878: pl. 23, 44-46) ilustrou bem o que hoje se entende por Urceolus cyclostomum (Stein) Mereschkowski. Há necessidade, pois, futuramente, de designar-lhe um lectótipo e definir o que é Urceolus cyclostomum (Stein) Mereschkowski validando, inclusive, o nome da espécie.

Material excluído:

Acusmonas pluvialis Skvortzov, Quarterly Journal of the Taiwan Museum 22: 231, fig. 15. 1969 - falta de informação na descrição e na ilustração que permitisse avaliar o material.

Eneidamonas applanata Skvortzov, Quarterly Journal of the Taiwan Museum 22: 227, fig. 5. 1969 - falta de informação na descrição e na ilustração que permitisse avaliar o material.

Skvortzov (1969) classificou na família Astasiaceae todos os gêneros descritos e propostos nesse trabalho. Os gêneros incluídos nesta família devem ser, entretanto, classificados na família Euglenaceae, por possuírem dois flagelos, dos quais um é ativamente móvel e emerge do reservatório e o outro, extremamente reduzido, jaz apenas vibrando no interior do mesmo reservatório. Mas, os gêneros Bicudomonas, Huberpestalozziamonas, Liangiana, Mariniamonas e Nilzamonas possuem um único flagelo inserido anteriormente.

A situação desses cinco gêneros é, entretanto, problemática no momento. O gênero Peranemopsis foi proposto por Lackey (1940) por diferir de Peranema unicamente na posse de um flagelo e não de dois; e foi classificado na família Peranemaceae. Porém, todos os demais gêneros classificados nesta família são constituídos por indivíduos que possuem dois flagelos de tamanhos diferentes entre si, um dos quais, seja o maior seja o menor, vai voltado para frente e o outro para trás enquanto o indivíduo se desloca. Qual dos dois vai voltado para frente, se o maior ou o menor, é uma característica usada para separar gêneros de Peranemaceae.

Bourrelly (1970) comentou a dificuldade em definir, de maneira precisa, o âmbito da família Peranemaceae. Concordamos plenamente. A presente localização dos cinco gêneros acima mencionados, todos propostos por Skvortzov (1969), na família Peranemaceae é bastante cômoda, porque todos se identificam com Peranemopsis quanto à posse de um único flagelo, porém, esta situação deverá ser revista com base na ultraestrutura do flagelo e/ ou de seu corpo basal ao microscópio eletrônico de transmissão. Conforme Leedale (1967), os gêneros ditos uniflagelados, em especial Peranemopsis, podem possuir um segundo flagelo cuja presença é de visualização muito difícil ou só pode ser confirmada pela permanência de seu corpo basal.

Embora em alguns trabalhos haja referência ao depósito de material no Herbário Científico do Estado "Maria Eneyda P. Kauffmann Fidalgo" (SP), tal fato jamais ocorreu. A bem da verdade, Boris V. Skvortzov coletava seus materiais e os mantinha vivos, em cultivos feitos utilizando o solo do ambiente de coleta e água de torneira. Tais cultivos eram deixados em sua própria sala de trabalho, à temperatura e luz ambiente, intocáveis por 10-12 dias, após o que eram examinados ao microscópio. Passando mais tempo, ou a água nesses cultivos secava e o material neles contido se perdia ou os frascos que continham os cultivos eram lavados ante a necessidade de mais recipientes para novos cultivos. De uma ou outra forma, os materiais-tipo de todas as espécies propostas por Boris V. Skvortzov jamais foram depositados em um herbário.

A despeito da coleta intensa realizada durante quase 40 anos no PEFI, nenhum material de Peranemaceae, exceto de Peranema, foi atualmente reencontrado. Todo presente trabalho foi baseado, portanto, quase que exclusivamente em material de literatura e, mais especificamente, nos trabalhos de Skvortzov (1966) e Skvortzov \& Noda $(1967,1968,1969,1970)$.

Praticamente todos os materiais constantes neste trabalho vieram da coleta de sedimento comumente rico em material orgânico, que constitui um tipo de hábitat propício para o desenvolvimento de organismos não-pigmentados, heterótrofos, como, por exemplo, os da família Peranemaceae. Em dois ou três casos, o material cresceu em cultivo de esterco eqüino em solução aquosa. As Peranemaceae pouco aparecem na água aberta e no sedimento raramente são numerosas. $O$ fato de deixar o material coletado "descansar" por 10-12 dias em meio sedimento-água favoreceu o crescimento de populações mais ou menos numerosas de espécies desses organismos e, principalmente, de representantes não encontrados logo após a coleta. 
Chave geral

1. Célula 1-flagelada

2. Flagelo circundado por um colarinho em forma de funil

(Urceolus) U. cyclostomus

2. Flagelo não circundado por colarinho em forma de funil . (Parmidium)

3. Cianelas presentes

*P.cyanophorum

3. Cianelas ausentes

4. Reservatório presente

*P. saprophyticum

4. Reservatório ausente

5. Célula achatada frontalmente, seção transversal elíptica

*P. obliquum

5. Célula não achatada frontalmente, seção transversal circular ou quase

6. Célula clavada, ovóide a ovóide alongada

7. Célula clavada, extremamente metabólica

* P. obovatum

7. Célula ovóide a ovóide alongada

8. Célula 1,5-1,6 vezes mais longa que larga

* P. simplicium

8. Célula ca. 3,3 vezes mais longa que larga

* P. sampaulense

6. Célula subfusiforme, fusiforme-alongada ou piriforme

9. Indivíduo não metabólico

*P. subnasutum

9. Indivíduo extremamente metabólico

10. Célula subfusiforme, pólo anterior acuminado, pólo posterior arredondado-truncado

* P. terrestre

10. Célula aproximadamente piriforme, pólo anterior arredondado, pólo posterior amplamente arredondado ou mamilado

* P. nasutum

1. Célula 2-flagelada

11. Pólos celulares iguais entre si

12. Bastonete faringeano ausente (Dinematomonas) D. griseola

12. Bastonete faringeano presente (Entosiphon)

13. Película estriada

14. Seção transversal da célula triangular

* E. triquetrum

14. Seção transversal da célula elíptica alongada

15. Margem da célula em seção transversal denteada ou crenulada

16. Margem da célula em seção transversal denteada *E. dentatum

16. Margem da célula em seção transversal crenulada

17. Margem da célula em seção transversal crenulada apenas de um lado *E. spiralis

17. Margem da célula em seção transversal crenulada em toda periferia

18. Célula subcircular * E. utriculariae

18. Célula elíptica ou oblonga

19. Célula elíptica

* E. longiusculum

19. Célula oblonga

* E. longistriatum

15. Margem da célula em seção transversal lisa

20. Célula amplamente elipsóide a quase esférica

* E. sampaulense

20. Célula subfusiforme ou oblonga

21. Célula subfusiforme

* E. pulchrum

21. Célula oblonga

22. Seção transversal da célula amplamente elíptica, estrias longitudinais, 6-8 visíveis ao longo da célula

* E. skvortzovii

22. Seção transversal da célula dorsiventralmente bastante comprimida, estrias levógiras, 3-4 visíveis ao longo da célula * E. anaerobicum

13. Película lisa

23. Célula em forma de raquete

* E. caudatum

23. Célula elíptica, oblonga, regularmente ovóide, obovóide alongada ou curto-cilíndrica 
24. Célula mais ou menos elíptica

25. Bastonete faringeano ca. $1 / 5$ do corpo celular * E. brevisiphon

25. Bastonete faringeano ca. $1 / 10$ do corpo flagelar * E. brevilanceolatum

24. Célula, oblonga, ovóide, regularmente obovóide, obovóide alongada ou curto-cilíndrica

26. Célula curto-cilíndrica *E. stagnalis

26. Célula oblonga, ovóide, regularmente obovóide a obovóide alongada

27. Célula oblonga * E. ellipticum

27. Célula regularmente ovóide, ovóide alongada, regularmente obovóide a obovóide alongada.

28. Célula regularmente ovóide ou ovóide alongada

29 . Bastonete faringeano curto ( $\leq 1 / 2$ do comprimento celular)

30. Bastonete faringeano $\leq 1 / 5$ do comprimento celular

30. Bastonete faringeano $\geq 1 / 2$ do comprimento celular * E. eichhorniae

29. Bastonete faringeano longo ( $\geq 2 / 3$ do comprimento celular)

31 . Bastonete faringeano $\leq 2 / 3$ do comprimento celular * E. fontinalis

31. Bastonete faringeano $\geq 4 / 5$ do comprimento celular * E. cymbellae *E. aerophyllum 28. Célula regularmente obovóide a obovóide alongada

32. Bastonete faringeano longo (ca. $4 / 5$ do comprimento celular) * E. merdae

32. Bastonete faringeano curto ( $\leq 1 / 2$ do comprimento celular)

33. Bastonete faringeano ca. $1 / 2$ do comprimento celular 33. Bastonete faringeano ca. $1 / 3$ do comprimento celular * E. pluvialis * E. nasutum var. nasutum

11. Pólos celulares desiguais entre si

34. Bastonete faringeano ausente.

(Peranema) P. inflexum

34. Bastonete faringeano presente (Heteronema)

35. Pólo posterior da célula fortemente acuminado, pontiagudo H. palmeri

35. Pólo posterior da célula amplamente arredondado H. acquae-purae

\section{Literatura citada}

Bicudo, C.E.M. \& Bicudo, R.M.T. 1970. Algas de águas continentais brasileiras: chave ilustrada para identificação de gêneros. Editora da Universidade de São Paulo e Fundação Brasileira para o Desenvolvimento do Ensino de Ciências, São Paulo.

Bourrelly, P. 1970. Les algues d'eau douce: initiation à la systématique: les algues vertes, v. 1. Éditions N. Boubée \& Cie, Paris.

Huber-Pestalozzi, G. 1955. Das Phytoplaknton des Süßwassers: Systematik und Biologie, v. 16, parte 4. E. Schweizerbart'sche Verlagbuchhandlung, Stuttgart.

Lackey, J.B. 1940. Some new flagellates from the Wood's Hole area. American Midland Naturalist 23: 463-471.

Leedale, G.F. 1967. Euglenoid flagellates. PrenticeHall, Englewood Cliffs.

McNeill, J., Barrie, F.R., Burdet, H.M., Demoulin, V., Hawksworth, D.L., Marhold, K., Nicolson,
D.H., Prado, J., Silva, P.C., Skog, J.E. \& Wiersema, J.H. 2007. Código Internacional de Nomenclatura Botânica (Código de Viena, 2006). (trad. oficial C.E.M. Bicudo \& J. Prado). RiMa Editora, São Carlos.

Menezes, M. 1993. New records of heterotrophic flagellates (Euglenophyta) from Brazil. Nova Hedwigia 56: 131-137.

Silva, P.C. 1960. Remarks on algal nomenclature, 3. Taxon 9: 18-25.

Skuja, H. 1939. Beitrag zur Algenflora Lettlands, 2. Acta Horti Botanici Unversitatis Latviensis 1112: 41-169.

Skvortzov, B.V. 1957. New and rare Flagellatae from Manchuria, Estearn Asia. The Philippine Journal of Science 86: 139-202.

Skvortzov, B.V. 1966. Species of genus Heteronema (Duj.) nob. (Peranemaceae, Euglenophyta, Flagellata) collected in N.E. China, Eastern Asia and in Brasil, South America with 34 figures. Quarterly Journal of the Taiwan Museum 19: 141-153.

Skvortzov, B.V. 1967. On new colourless Flagellata 
402

Hoehnea 37(2): 383-402, 37 fig., 2010

genus Huber-Pestalozziamonas gen. nov. Fam. Peranemaceae, Euglenophyta. The Bulletin of Japanese Society of Phycology 15: 16-21.

Skvortzov, B.V. 1969. New and little known genera of colourless flagellates of Fam. Astasiaceae, Euglenophyceae recorded in 1954-1968 from N.E. China and Brasil. Quarterly Journal of the Taiwan Museum 22: 223-239.

Skvortzov, B.V. \& Noda, M. 1968. On colourless flagellata of genus Entosiphon Stein, Fam. Peranemaceae, Euglenophta collected in São Paulo, Brasil, South America. The Journal of Japanese Botany 43: 164-168.

Skvortzov, B.V. \& Noda, M. 1969. On species of genus Entosiphon Stein, Fam. Peranemaceae,
Euglenaceae from São Paulo, Brasil, 2. Science Reports of Niigata University, series D, 6: 8792.

Skvortzov, B.V. \& Noda, M. 1970. On species of genus Entosiphon Stein, Fam. Peranemaceae from São Paulo, Brazil, South America. Science Reports pf Niigata University, series D, 7: 5761.

Stein, F.R. 1878. Der Organismus der Flagellaten nach eigenen Forschungen in Systematischer Reihenfolgen bearbeitet, 1: den noch aegeschlossenen allgemeinen Theil nebst Erklärung der sämmtlichen Abbildungen enthaltend. Verlag von Wilhem Engelmann, Leipzig. 